\title{
Impacts of Smart Grid Concept on Energy Industry
}

\author{
Marek Adamec, Pavel Pavlatka, Milan Kloubec, Oldrich Stray \\ Department of Economics, Management and Humanities, Czech Technical University, Prague, Czech Republic \\ Email: marek.adamec@fel.cvut.cz
}

Received September 29, 2012; revised February 4, 2013; accepted February 15, 2013

Copyright (C) 2013 Marek Adamec et al. This is an open access article distributed under the Creative Commons Attribution License, which permits unrestricted use, distribution, and reproduction in any medium, provided the original work is properly cited.

\begin{abstract}
Smart grid (SG) is a term that has recently become widely discussed along with the boom of renewable resources (RES-E) and with brand new approach to energy industry. Such phenomena are results from $\mathrm{CO}_{2}$ emissions mitigation and fight against global climate change, as it is discussed e.g. in [1]. Most of the RES-Es work on principles that do not enable the control of their generation. This fact impacts massively on the electricity grid. It is publicly known that the relatively massive development of non-manageable resources, along with the long-term increasing of energy demand, puts higher and higher requirements on the transmission system's transport capacity. This problem becomes more visible e.g., with future plug-in electric vehicles (PEV) or local renewables (RES-E) expansion. Task for today's engineers is to solve the sustainability of energy industry. The smart grid concept provides one possible way. Our paper therefore discusses main aspects of SG implementation, which are not often publicly discussed. Our paper describes SG concept that compiles with approach to the decentralized power industry, together with nodal prices occurrence. The local congestions in the grid as well as growing amount of consumption (connected with electric vehicles expansion) and local micro-generation can result in the price nodality. Therefore electricity price can differ according to local conditions from price in global grid. The mathematical description of conditions influences grid nodality follows. In the end of the manuscript, the new way of electricity pricing is proposed.
\end{abstract}

Keywords: Advanced Metering Management; Decentralized Energy Industry; Electric Vehicles; Nodality; Smart Grid; Smart Local Price; Social Welfare

\section{Introduction}

In the European Union (EU) predicted expansion of micro RES-E as well as electro-mobility will cause massive changes in electric system stability. Today's grids and price management are designed according presumption, that large manageable resources transport electricity from high-voltage grids to low-voltage distribution grids. According to our opinion, such facts result in brand new approach to energy industry - decentralized energy industry which absolutely complies with implementation of SG. Moreover the system of new price management will have to be established under massive SG concept implementation as well.

Real time compliance between generation and consumption must be ensured to guarantee grid stability. Classical electricity resources that utilize some fuel represent resources manageable according to grid requirements. On the other hand some kinds of RES-Es are fully dependent on a climate conditions (non-manageable). Everyone knows the saying "you cannot command wind and rain". Under condition of growing social welfare and current Western living standards we cannot accept its change into "adapt to wind and rain". It is quite obvious that such a state would be absolutely unacceptable for both industry and households with. Impact of energy industry to social welfare is discussed in [2,3]. SG can be simply described as a network which is able to respond to the current state in the grid at every moment [4]. Infrastructure that enables this concept is known as advanced metering management (AMM). AMM represents functional system of measuring devices with advanced functionality which enables direct demand management as well as two-way communication.

\subsection{Main Differences between SG and Classical Grids}

There are some phenomena for that the former concept of electricity grids is not prepared. The most important aspects are:

- Growing divergence between the production and consumption diagrams. Today's electricity grids were designed according to presumption that generation of 
electricity is in real time managed according to consumption diagram. Generation in wind and photovoltaic power plants depends on local weather conditions.

- Therefore uncertainty on the generation side according to local weather conditions and installed capacity of particular resource must be considered by distribution system operators (DSO) or traders purchasing electricity from RES-E. In case of Czech energy industry the maximum/minimum of possible influence by $1000 \mathrm{MW}$ in photovoltaic power plant (PV) according to [5] is on Figure 1.

- Growing divergence between the localization of production and consumption. Maximization of RES-E availability factor forces investors to build wind power plants according to specific weather conditions, not according to grids requirements. Therefore large amount of electricity is transported via transmission grid [6].

- Impossibility of storage is one of the implicit features of electricity. This aspect influences especially electricity transmission and distribution. Under condition that vast majority of resources are manageable; generation is at any time managed according to consumption. Growing fraction of non-manageable resources represents incentive for electricity storage capacities that are still too expensive [7].

- Universal presumption that has been used for designing of today's grids is model electricity flow from large generation resources connected to high voltage parts of grid. In the decentralized energy industry the growing number of local micro generation could cause overflows from low voltage to high voltage grids.

- Any investment is connected with very difficult procedure of permitting procedure from side of land owners. Therefore any investment into grid capacity enlargement (to avoid threaten bottlenecks) represents very long and expensive procedure.

- Growing amount of electric vehicles (EV) will cause systematic overloads of current grids.

\subsection{RES-E Volumetric Impact}

Considering the growing share of RES-E we logically come to the conclusion that growing percentage of generation becomes an independent variable, together with an increasing share of these non-manageable resources involved in the grid. Consumption, on the contrary would become partly dependent variable.

Moreover large RES-E installations are mostly concerned to some areas with suitable weather conditions. Transporting capacity is in the same time strictly limited by physical conditions [8]. This could under some unlike operational conditions result in congestion occurrence, because only $G_{\text {managable }}^{\prime}(t)$ can be utilized as ancillary services. Therefore electricity power transport, necessary for grid stability, can be limited by such bottlenecks. Mentioned fact will get worse with growing amount of nonmanageable resources. This aspect could result in massive impact on the geographical electricity availability differences.

From long term strategic grid planning point of view the real occurrence of bottleneck depends on N-1 criterion fulfillment as it is described e.g. in [9]. Under this criterion the interruption of $\mathrm{N}-1$ criterion can cause in virtual bottleneck. Overload of this bottleneck results not in blackout, but in interruption of $\mathrm{N}-1$ criterion which massively jeopardizes grid stability.

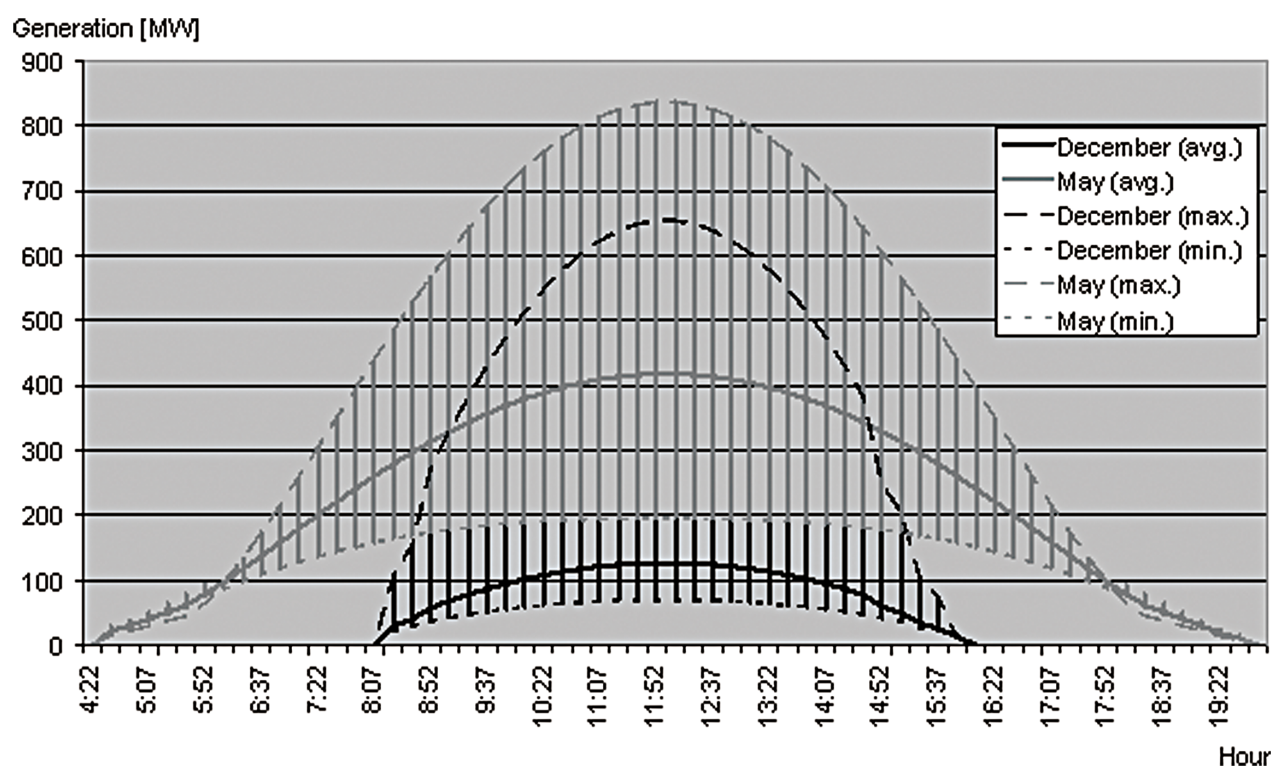

Figure 1. Maximal, minimal and average daily uncertainty originating in $1000 \mathrm{MW}$ installed capacity in PV in Czech Republic [5]. 


\subsection{AMM}

It is obvious that management of local consumption is most important aspect of decentralized power industry. The equipment of AMM devices is necessary but not the sufficient for successful SG concept implementation. SG concept in the same time is supposed to bring large savings by the means of AMM (e.g. dynamic load control as written in [10]). According to our opinion appropriate price management will represent the only way how to motivate consumer to behave (and manage his consumption) according to needs of the grid. It is not admissible to constrained consumers in their free consumption behavior by ordering when and how much electricity are they allowed to consume. Therefore in this manuscript the price management is proposed to serve as an appropriate method of demand management in the decentralized power industry.

\section{Methods}

As it is written above we have identified two main possible impacts of new grid concept. The first, described is necessity of brand new electricity grids management, mostly known as Smart Grids (SG) concept. The following is decoupling of prices from single zone to more nodal prices. Both described facts relate together. For their theoretical support we will have to establish approach based.

The above mentioned facts result in massive changes in price management after SG implementation. The management of $C *(t)$ is made by the means of price changes according. The following figures show princi- ples of price and volume dependence by market equilibrium. The following cases have in real grid not the same probability, but in general all can occur.

\section{Local Grid vs. Global Grid}

Moving to real (non-closed system), according to above mentioned facts electrical grids naturally incline to decouple into more local grids by the growing amount of transported electricity.

Local grid for each customer differs. It is divided from global grid by nearest local congestion (LC).

$$
\begin{gathered}
C *(t)=G_{\text {non-manageable }}(t)+G *_{\text {manageable }}(t)+G_{G}(t)-L(t) \\
G_{G}(t) \leq \mathrm{LCC}
\end{gathered}
$$

where $C(t)$ is maximal electricity consumption in some local grid, $G G(t)$ is available generation capacity in global grid, $G_{\text {non-managable }}(t)$ is generation in non-manageable local resources, $G *_{\text {manageable }}(t)$ represents generation in manageable local resources, $L(t)$ are losses in local grid and LCC is local congestion capacity. Operand * (star) marks time variable in real grid which can be managed by local AMM devices in the SG concept.

To be more specific this Equation (1) is correct under condition of no congestions in the grids. To involve congestion the grid splits to more local grids. Example of local grid is on Figure 2. Bottleneck is caused by insufficient conductor capacity according to $[10,11]$. This fact as well as LCC is set by physical conditions (according to conductors dimensioning methodology $[12,13])$. The condition (2) represents condition for Equation (1).

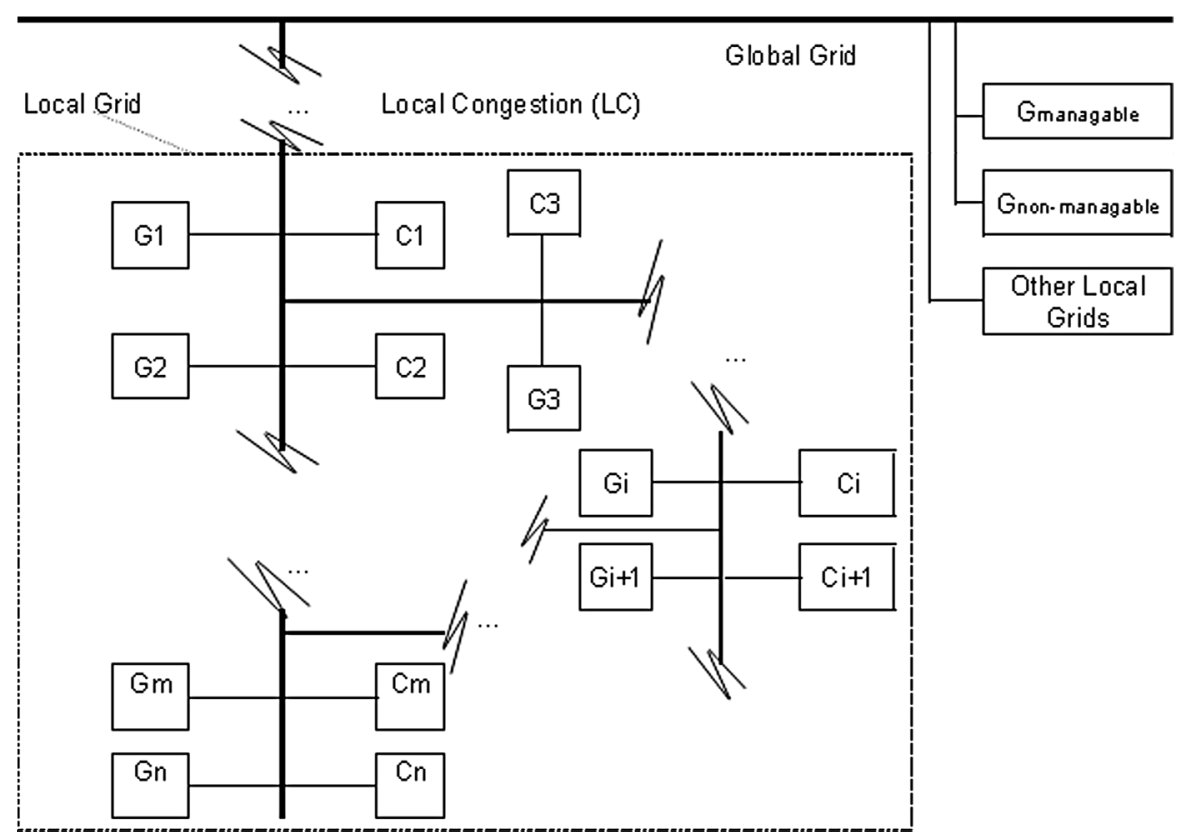

Figure 2. Local electrical grid is element of global grid separated by congestion. 


\section{Theory}

As it is written above we have identified two main possible impacts of new grid concept. The first is necessity of brand new electricity grids management mostly known as Smart Grids (SG) concept. The following is decoupling of prices from single zone to more nodal prices, and in more details with direct impacts to customers.

The mentioned facts will result in massive changes in price management after SG implementation. The management of $C *(t)$ can be, according to authors, made by the means of price changes.

\subsection{Local Grid Consumption Surplus}

In case local consumption intends to transgress against Equation (2) the grid stability can be ensured as follows: Critical point is LCC transgress.

- Local generation $G *{ }_{\text {manageable }}(t)$ increase. This possibility can be used only in local areas where manageable resources (e.g., micro generation) are presented.
Such generation devices shall be therefore equipped by AMM management as well as consumers.

- Consumption $C *(t)$ decrease. The prices in local grid in that case decouples from global ones. Price increase must at any time ensure sufficient consumption decrease.

As it is shown on Figure 3, existence of LCC would cause price decoupling $(\Delta P)$ between local and global grid. Shown increment of consumer electricity price will secure stability of the grid, because local consumption will be changed from first stabilized state $C_{\mathrm{g} 0}$ to $Q_{\mathrm{g} 1}$ which is maximal volume of electricity that can be consumed without jeopardizing of grid stability.

\subsection{Local Grid Generation Surplus}

LCC can be also transgressed by local generation, $G_{\text {non-managable }}(t)$. In that case for grid stability there are following possibilities:

Critical point is production in local non-manageable resources impossible to export via LCC.

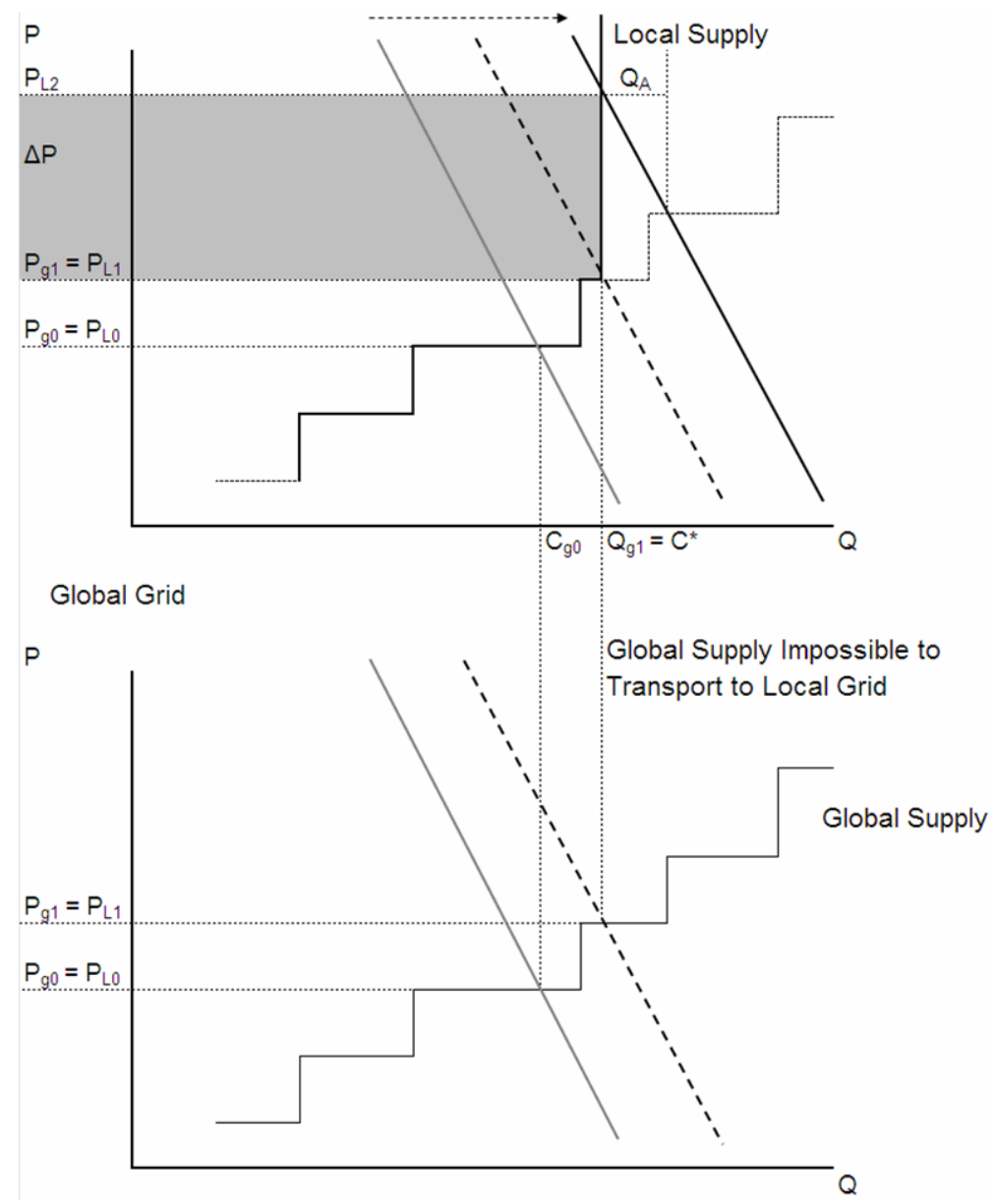

Figure 3. Local grid consumption surplus. $Q_{\mathrm{A}}$ represents avoided amount of electricity that would cause overload without AMM management. The dashed part of local supply curve can be according to authors cut by AMM. Electricity price is changed by the market from $P_{0}$ price level to $P_{1}$ price level in both local and global grid. Price level $P_{\mathrm{L} 2}$ is managed by the means of AMM and occurs only in local grid to secure grid stability. 
- Local generation $G *_{\text {manageable }}(t)$ decrease. This possibility can be used only in local areas where manageable micro generation is presented. Such generation devices shall be therefore equipped by AMM management as well as consumers.

- Consumption $C *(t)$ increase. The prices in local grid in that case decouples from global ones. Price decrease must at any time ensure sufficient consumption increase.

As it is shown on Figure 4, existence of LCC would cause price decoupling $(\Delta P)$ between local and global grid. Shown descent of consumer electricity price will secure stability of the grid, because local consumption will be changed from first stabilized state $C_{\mathrm{g} 0}$ to $Q_{\mathrm{g} 1}$ which is minimal volume of electricity that can be consumed without jeopardizing of grid stability.

\subsection{Global Grid Generation Surplus}

Another case is represented by situation when Equation (2) intends to be violated by insufficient consumption in global grid. For grid stability there are following possibilities:

Critical point is LCC transgress in combination with global grid ancillary services capacity.

- Global grid generation shall be decreased. This response could be done by ancillary services descent or by management of resources (not only ancillary ones) equipped by AMM. We deal with presumption that ancillary services will not have to be equipped by AMM because they are managed by the needs of grid according to the contracts with TSO.

- Consumption $C *(t)$ in local grid can increase only to the limit set by Equation (2) to avoid overload of LCC capacity. Additional increment of consumption when all LCC is used shall happen in other parts of global grid.

This implies decrease of global price. Therefore price in local grid decouples again from global grid prices which decreases to stimulate consumption in other grids without congestion (with sufficient capacity).

As it is shown on Figure 5, existence of LCC would cause price decoupling between local and global grid. Shown decoupling of consumer electricity price will stop the growing volume of electricity consumption on level $Q_{\mathrm{g} 1}$ which is maximal volume of electricity that can be consumed without jeopardizing of grid stability to consume at least local production and not to overload LCC.

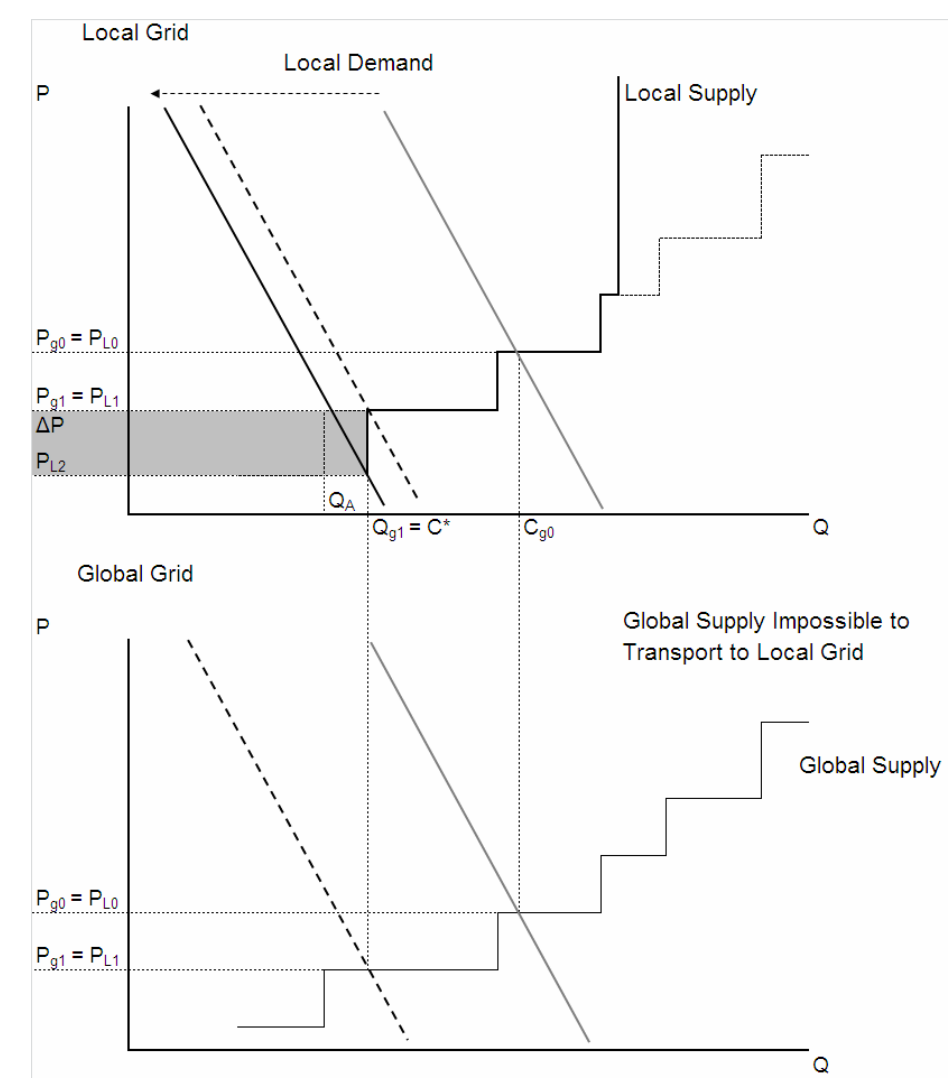

Figure 4. Local Grid Generation Surplus. $Q_{\mathrm{A}}$ represents avoided amount of electricity that would cause overload without AMM management. The dashed parts of local supply curve are cut by AMM. Electricity price is changed by the market from $P_{0}$ price level to $P_{1}$ price level in both local and global grid. Price level $P_{\mathrm{L} 2}$ is managed by the means of AMM and occurs only in local grid to secure grid stability. 


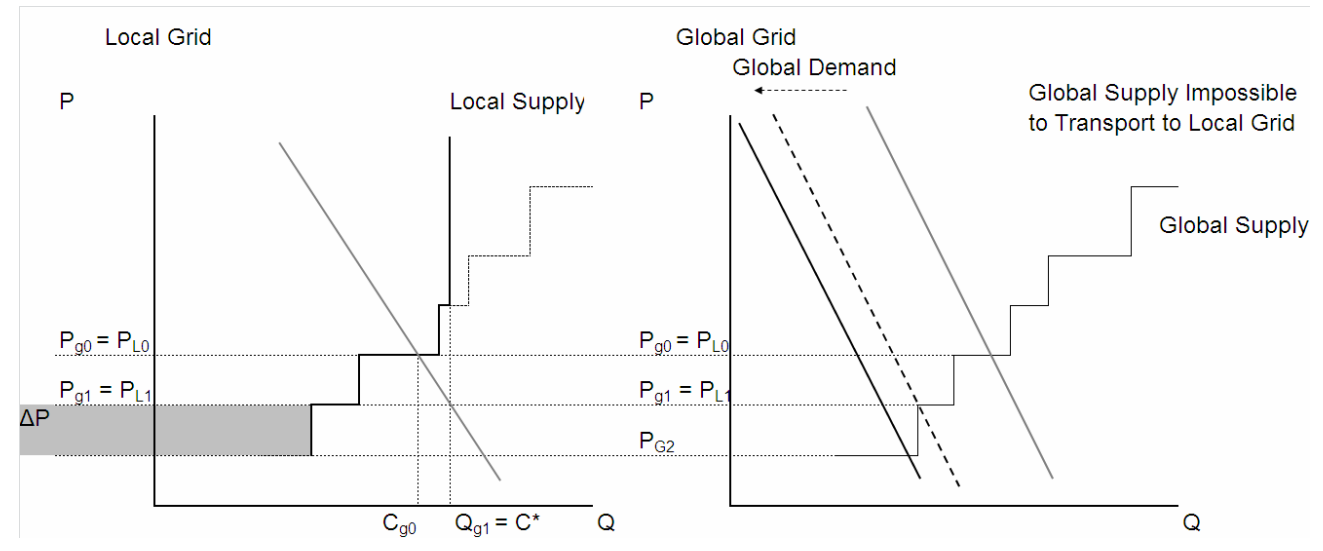

Figure 5. Global grid generation surplus. Electricity price is changed by the market from $P_{0}$ price level to $P_{1}$ price level in both local and global grid. Price level $P_{\mathrm{G} 2}$ occurs only in global grid and by the means of AMM will not occur in the local grid to secure grid stability.

\subsection{Global Grid Consumption Surplus}

In that case all manageable resources will have to increase its generation.

Critical point is production in local non-manageable resources impossible to export via LCC.

- Decentralized micro generation shall increase. Limit for maximal possible regulation from (decentralized micro generation resources) is set by local LCC. In other words sum of LCC of all local grids set the maximal regulation energy provided by decentralized manageable micro generation resources equipped by AMM (not their aggregate capacity).

- In the same time resources connected to global grid equipped by AMM devices shall be forced to increase their generation as well as ancillary services.

- Consumption in all local grids shall decrease. This can be caused by price increase in all local grids.

As it is shown on Figure 6, existence of LCC would cause price decoupling between local and global grid. Shown decoupling of consumer electricity price will stop the growing volume of electricity consumption on level $Q_{\mathrm{g} 1}$ which is maximal volume of electricity that can be consumed without jeopardizing of grid stability to consume at least local production and not to overload LCC.

\section{Results}

\subsection{Relation between Economic and Technical Criterion}

Following above mentioned methodology an instrument for grid management in the SG concept is $G *{ }_{\text {manageable }}(t)$. The question is from which point of view the management of consumption shall be made. A very little discussed fact is that the management of AMM purely based on the needs of the network may not at any time represent the optimal management in the way of minimizing customer electricity prices. What the transmission and distribution system need is the equal balance of power to enable their operation. The resulting need for grid stability may not correspond with the needs of traders and consumers. Our analysis is based on presumption that electricity price minimization together with load descent [13] represents incentives to social welfare increase because of fact that economic feasibility is set by customers savings. Moreover connection of nodal prices and more effective capital allocation with social welfare has been described e.g. in [14]. This therefore establishes multi criterion assessment of SG implementation. The technical needs of transmission and distribution networks (according methodology Equations (1) and (2)) shall therefore set boarders for the market oriented pricing. Within such technical boundaries which must be valid at any time, there exists opportunity for benefits $B_{\mathrm{t}}$ realized without jeopardizing of the grid stability. The effort for the future would therefore be merging the interests of traders and grid operators in the way that the price at any time (either local or global) provokes exact demand to ensure the balance of power in the grid. The change of social welfare can be expressed by Equation (3). According to [15] the aggregate NPV for customers can influence the change of social welfare. The relation depends on the value of externalities [16], because relationship in Equation (3) represents only the pure cash benefit for customers.

$$
\Delta \mathrm{SWF} \approx \sum_{k=1}^{N}\left(\mathrm{NPV}_{\mathrm{CUS}}\right)_{k}=\sum_{k=1}^{N}\left(\sum_{t=t_{0}}^{T} \frac{B_{t}-\text { Cost }_{t}}{(1+d)}\right)_{k},
$$

where $\triangle \mathrm{SWF}$ is change of social welfare, $\mathrm{NPV}_{\mathrm{CUS}}$ is net present value of benefits brought by $\mathrm{SG}$ implementation during its lifetime $T$ to the customers, $B_{\mathrm{t}}$ are benefits of SG implementation in the year $t$ to the customers, Cost $t_{t}$ are costs of SG implementation in the year $t$ to the customers, $N$ represents number of customers and $d$ is discount rate of customers. 


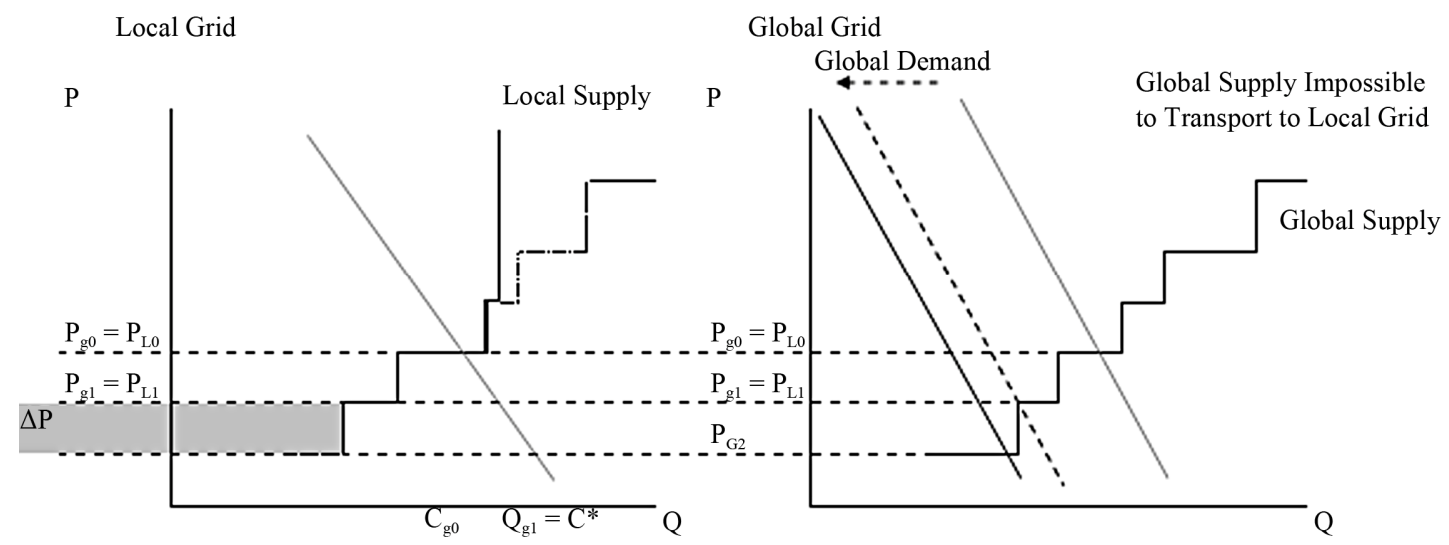

Figure 6. Global grid consumption surplus. Electricity price is changed by the market from $P_{0}$ price level to $P_{1}$ price level in both local and global grid. Price level $P_{\mathrm{G} 2}$ occurs only in global grid and by the means of AMM will not occur in the local grid to secure grid stability.

It is important to underline, that costs of new AMM devices decline according to methodology of technological learning described in [17].

\subsection{Dimensioning of Conductors in Local Areas}

The grid management is critically set by local-grid conductor dimensioning. The critical criterion is value of electrical current. The electrical current sets at the same time value of energy and also value of thermal strain of conductors. According to methodology used for conductor dimensioning [12] Czech distribution companies uses special coefficients for conductor dimensioning. Such coefficients originate in fact that the consumption times of vast majority of appliances differs. Therefore it is not necessary to calculate capacity of conductors to sum of installed capacity (maximal electrical current) of all appliances. Therefore the maximal capacity/current for that the conductors are dimensioned is set generally by following equation

$$
L_{\mathrm{Tm}}=\operatorname{coef} \cdot L_{\mathrm{m}},
$$

where $L_{\mathrm{Tm}}$ total load of group of consumer (e.g., village), coef is applicable coefficient of simultaneousness and $L_{\mathrm{m}}$ is maximal average household load.

The coefficient $c_{\mathrm{t}}$ is used for estimation of time simultaneousness of consumption in the group of more customers (places of offtake) e.g., village. According to [11] the common value of ct is 0.38 for flats $c_{\mathrm{tf}}$ and 0.6 in groups of solitaire buildings $c_{\text {th }}$. Annual consumption of average household in the EU according [18] is less than $3000 \mathrm{kWh}$ (without central heating and Plug-in Electric and Hybrid Vehicles charging) per year. Consumption of average household during day, regarding typical appliance consumption, daily usage and percentage of ownership in the segment of households is on [19]. When we suppose whole village, the final consumption will be set by sum of all households multiplied by $c_{\mathrm{t}}$.
After massive expansion of EV (our presumption 10\% of electric vehicles in 2020) the situation with conductor capacity would dramatically change. EV charging current would increase the daily consumption of region. Moreover coefficient of simultaneousness would be much higher (according to our research about $0.9-0.8 c_{\mathrm{te}}$ ) because vast majority of consumers would charge EV during the same times in the place where they live or work.

\subsection{Case Study Results}

Our approach in this viewpoint is to evaluate impact of EV expansion in 1150 household village in Czech Republic. We suppose $10 \%$ penetration of households by EV. We use standard methodology according to [11]. The used data are shown in Table 1. Dimensioning of feed conductors is set by maximal total consumption of 1150 households provided: 40 flat houses $\left(n_{\mathrm{f}}\right)$ with 20 flats, 150 double household houses $\left(n_{\mathrm{dh}}\right)$ and 50 single household houses $\left(n_{\mathrm{sh}}\right)$. Maximal consumption of average household is $C_{\mathrm{m}}$ and maximal total load is $L_{\mathrm{Tm}}$ set before $\mathrm{EV}$ expansion by Equation (5) and $L_{\mathrm{Tme}}$ after expansion by Equation (6).

$$
\begin{aligned}
& L_{\mathrm{Tm}}=c_{\mathrm{t}} \cdot L_{\mathrm{m}} \\
& =\left(20 \cdot c_{\mathrm{tf}} \cdot n_{\mathrm{f}} \cdot c_{\mathrm{th}}+2 \cdot c_{\mathrm{tf}} \cdot n_{\mathrm{dh}} \cdot c_{\mathrm{tf}}+n_{\mathrm{sh}} \cdot c_{\mathrm{th}}\right) \cdot L_{\mathrm{m}} \\
& L_{\mathrm{Tme}}=L_{\mathrm{Tm}}+c_{\mathrm{te}} \cdot\left(20 \cdot n_{\mathrm{f}}+2 \cdot n_{\mathrm{dh}}+n_{\mathrm{sh}}\right) \cdot L_{\mathrm{e}},
\end{aligned}
$$

where $L_{\mathrm{m}}$ is maximal average household load, $L_{\mathrm{e}}$ is average charging consumption of electric vehicle (both corrected by ownership percentage).

This $c_{\text {te }}$ coefficient can be changed by the means of demand side management (DSM) also [20].

It is shown on Table 2 that influence on total village feed dimensioning is almost $30 \%$. Our survey moreover showed that effective DSM (and load shifting) connected with EV would be jeopardized by large fees for reserved capacity applied in distribution systems. Therefore solution only by the means of SG in this would be difficult. 
Table 1. Inputs for case study.

\begin{tabular}{cc}
\hline Case Study Inputs & Value \\
\hline Number of falt houses $\left(n_{\mathrm{f}}\right)$ with the 20 flats & 40 \\
Number of bouble houses $\left(n_{\mathrm{dh}}\right)$ & 150 \\
Number of single houses $\left(n_{\mathrm{sh}}\right)$ & 50 \\
Number of households in the nodel area $(n)$ & 1150 \\
Coefficient of simultaneousness between falts $\left(c_{\mathrm{tf}}\right)$ & 0.38 \\
Coefficient of simultaneousness between households $\left(c_{\mathrm{th}}\right)$ & 0.6 \\
Coefficient of simultaneousness between electromobiles $\left(c_{\mathrm{te}}\right)$ & 0.85 \\
\hline
\end{tabular}

Table 2. Dimensioning impact of EV.

\begin{tabular}{ccc}
\hline & $\begin{array}{c}\text { Household with 100\% } \\
\text { Appliance Ownership }\end{array}$ & Average Household \\
Household Maximal Load [W] & 1300 & 900 \\
Household maximal electromobility load $[\mathrm{W}]$ & 750 & 75 \\
Dimensioning of conductors for 1150 households $[\mathrm{kW}]$ & - & 253 \\
Dimensioning of conductors 1150 households $[\mathrm{kW}]$ & - & 326 \\
\hline
\end{tabular}

Massive DSM would therefore be needed. This fact would results in incentives for massive decentralized Combined Heat and Power units (micro CHP).

\section{Discussion}

\subsection{Trading and Distribution Optimization}

If we proceed from the assumption that the AMM allows demand management according to the needs of the network then there should be the merger of the needs of trading and distribution. In chapter 4.1 we have mentioned that economic criterion should be preferred. The optimal state consists in merger of trading and distribution way of demand management. The most significant conceptual change here is that this management will constitute the pulling of consumers into real electricity trading at almost the spot market level. The determinant for these situations will be both a large supply of large RESE installations supplying to the transmission network as well as supplies from small decentralized sources. Their growing share may then lead to the collapse of the price level in each local area and real price decoupling. Such a situation is far different from the current model of centrally controlled systems. In other words, an intelligent with a large number of dispersed renewable energy sources and growing local consumption without extensive investment into network expansion will represent an intelligent network with many nuclei of minor importance, possessing different minor balances, different price levels and different responses to either energy network changes or weather changes. This fact will be the biggest strategic change in energy systems over the next decade.

\subsection{Local Third Party Access}

The predicted price decoupling will result, according to the authors of this article, in the need to establish an entirely new concept of Local Third Party Access (LTPA). Only this new concept of local concurrence of more traders will allow the introduction of SG in accordance with the accepted concept of TPA. The described concept of SG nevertheless presents not a final stage of development from the perspective of energy supply to end users because it does not consider the competition between different kinds of energy. Implicitly, however, it contains the possibility of its introduction. The little Combined Heat and Power (CHP) units consuming gas can substitute electricity consumption. These would come to the LTPA concept as a closing power source. From the known gas prices, the AMM systems would be able to calculate the costs of producing electricity in a decentralized CHP unit which also produces heat. In this case, it would already be a multi Smart Grid (MSG).

These challenges are tasks that have so far been very unfairly neglected in the public debates and scientific work of many prestigious Western universities. This is therefore an area for small teams researching the anticipated effects of modern trends in power engineering, often called a clean technology.

It is therefore possible for the scope of small units and teams investigating the anticipated effects of modern trends that is also often called as a clean technology.

\subsection{Electricity Trading}

A current trader having in its portfolio electricity consumers must constantly cover their consumption curve. In the case of increasing installations of renewable resources on the side of the consumer (so-called "behind meter"), this curve is, along with its trade obligations/ liabilities to the market, burdened with more uncertainty. In most cases the electricity to cover the consumption is 
provided by long-term contracts within the managed portfolio, to eliminate possible market risk of open positions and is optimized from the perspective of volumetric risk, which complies with results of [21]. The variable (called "residual") part of the diagram creates a short-time position on the organized spot market. This, however, resolved trade commitments in the time span that precedes the moment of delivery by more than 24 hours. Due to the aforementioned uncertainties, there is a change in the coverage of consumption that will result in deviation on the trader's side. This deviation is currently being dealt with by activating regulatory services from the system.

The possible lack of transportation capacity and other constraints would cause high volatility in prices in the settlement of deviations and ultimately can lead to considerable market risk for trader.

\section{Conclusions}

According to above mentioned facts growing number of micro RES-E devices as well as growing consumption will result in potential overloading of some conductor in the distribution grid. More general such phenomena can occur in transmission grid as well. For instance, growing amount of wind power plants installed in Northern Germany overload coss-border connections between Germany and Czech Republic because of transports of electricity from the north to the south of Europe [22]. In extremes it could lead to total collapse of transmission grid under some conditions, because n-1 criterion is not fulfilled.

Mentioned facts would therefore request the new way of decentralized grid management by the means of AMM. This fact according to authors of this manuscript complies with SG concept. The following impacts of SG were therefore identified by our research.

\subsection{Price Management Methodology}

Situations described in chapters 3.1-3.4 results in price decoupling between local and global grid. The difference (marked as $\Delta P$ ) can be therefore described as AMM management incentive that is purposed to manage consumption in the way of grid stability assurance (also called DSM). The real structure of this DSM executed by AMM devices will set value of future costs and benefits as well as value of future social welfare according to Equation (3). Because of electricity market structure, the management shall be made price signals not involved into liberalized electricity price or regulated one.

$$
P_{\mathrm{f}}=P_{\mathrm{Lib}}+P_{\mathrm{Reg}}+\Delta P_{\mathrm{AMM}}
$$

where $P_{\mathrm{f}}$ represent total consumer price $P_{\text {Lib }}$ represents liberalized part of electricity price results in electricity trading, $P_{\text {Reg }}$ represents regulated part of price and $\Delta P_{\mathrm{AMM}}$ represents AMM management incentive.

The real price-signals as provided by AMM system (connected to whole SG concept) by $\Delta P$ price signals are shown on Equation (13) and apparent on Figures 3-6. According to our research such signals represents the only way for the demand response management in the framework of today's liberalized electricity retail market. Direct regulation of demand would suspend consumer's free choice of electricity consumption, which jeopardizes growth of social welfare. On Figure 7 it can be seen time variation of consumption ant it's influencing by shift able consumption (mostly heating). The spread between the curves represents potential for intelligent smart demand response.

Transportation of large amounts of electricity (originnated in local surplus of generation) therefore increases probability of congestion somewhere in the grid. The situation can be therefore improved by consumption escalation in near local grids. This could cause price regional gradient of retail price which was described in Chapters 3.1-3.4.

It is obvious that described concept of price management will be costly. The real costs and benefits depend on point of view. Different costs and benefit impact on each market participant differently. When we include the funding, implementation and development of these networks, it is clear that in the end, the consumer will be final investor. On the other hand, customer will obtain opportunity to become active participant in the process of implementation of these intelligent technologies. This fact should bring a motivation system of incentives for customers to establish massive energy and money savings. In the current liberalized system, the closest trading partner for the consumer is a trader and for this reason, now it seems to be necessary to include electricity traders to preparation of SG concept.

\subsection{Overloading of Conductors}

Another identified conclusion, also discussed in [22], is risk of conductors overloading. One example manifesting this fact-overloading of conductors by EV penetration is

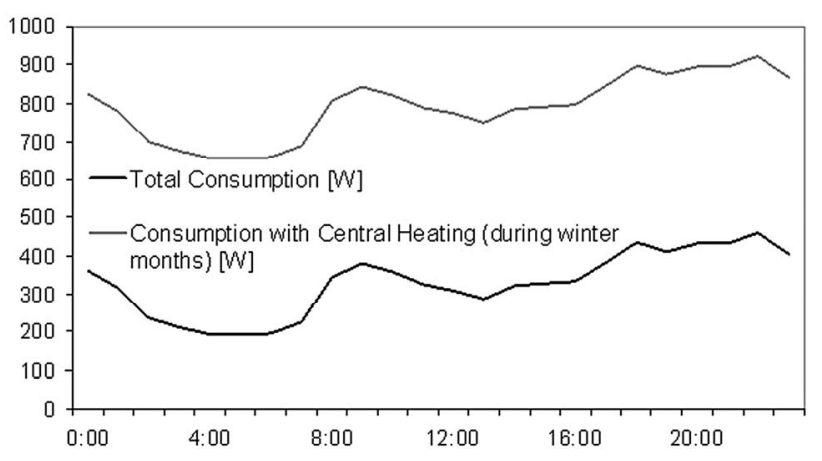

Figure 7. Consumption of average household [19]. 
described in this paper. According to our analysis, apparent risk of congestion provoked by expansion of EV jeopardizes electricity grids, because of large coefficient of simultaneousness of EV charging. The AMM devices with SG concept implementation would again help with such phenomenon. This fact supports our results about nodal prices occurrence after massive decentral generation/consumption capacities.

Another solution could be provided by micro CHP (combined heat end power units) installations. MicroCHP is a specific form of CHP with low performance designed mainly for individual households. As a replacement of a standard domestic gas boiler, it generates power for consumption in the home or for selling it with the feed-in tariff. In dependence of natural gas and electricity prices such concept in connection with smart tariffs application is on the edge of economical effectiveness according to net present value (NPV) method or real-option approach. But increasing cost of power transport (contained in regulated part of price according Chapters 4.2 and 4.3) due to the higher capacity needs of e.g. EV would cause increment of retail electricity price. This fact could afterwards result in the higher economic purpose of these micro-CHP devices and in their massive implementation.

\subsection{Open Questions}

Ancillary services can merge with AMM equipped resources using the appropriate trading system. Appropriate calculations of economic effectiveness as well as impacts to social welfare of such services will have to be provided by our future research.

Additional open question is most appropriate way of AMM financing. The methodology of AMM financing will be needed for solving of time divergence between cash outflow originating in AMM CAPEX and its progressive future discounted savings for electricity customers. Some financing method will have to be used, as it was presented in [15].

\section{Acknowledgements}

Authors of this work thank the Department of Economics, Management and Humanities, Czech Technical University in Prague for support during the data mining and methodology formulation. This support was enabled by the means of Grant provided by Czech Technical University in Prague, SGS13/137/OHK5/2T/13.

\section{REFERENCES}

[1] C. W. Gellings, "The Smart Grid: Enabling Energy Efficiency and Demand Response," The Fairmont Press, Lilburn, 2009.

[2] E. Sauma and S. Oren, "Do Generation Firms in Restruc- tured Electricity Markets Have Incentives to Support Social-Welfare-Improving Transmission Investments," Energy Economics, Vol. 31, 2009, pp. 676-689. doi:10.1016/j.eneco.2009.01.015

[3] X. Zou, "Double-Sided Auction Mechanism Design in Electricity Based on Maximizing Social Welfare," Energy Policy, Vol. 37, 2009, pp. 4231-4239. doi:10.1016/i.enpol.2009.05.019

[4] M. Adamec, P. Pavlatka and O. Stary, "Costs and Benefits of Smart Grids and Accumulation in Czech Distribution System," Energy Procedia, Vol. 12, 2011, pp. 67-75. http://www.sciencedirect.com/science/article/pii/S187661 0211018376

[5] PVGIS Model. http://sunbird.jrc.it/pvgis/apps/pvest.php?lang=sk\&map=e urope

[6] Press Release by ČEPS (Czech Transmission System Operator). www.ceps.cz

[7] M. Adamec, P. Pavlátka and O. Starý, "Costs and Benefits of Smart Grids on Liberalized Markets," Journal of Electronic Science and Technology, 2012.

[8] F. Vanek and L. Albright, "Energy System Engineering," McGraw-Hill, New York, 2008.

[9] M. Nooij, B. Baarsma, G. Bloemhof, H. Slootweg and H. Dijk, "Development and Application of a Cost-Benefit Framework for Energy Reliability Using Probabilistic Methods in Network Planning and Regulation to Enhance Social Welfare: The N-1 Rule," Energy Economics, Vol. 32, 2010, pp. 1277-1282. doi:10.1016/j.eneco.2010.06.005

[10] Ch. Liu, Q. Zeng and Y. Liu, "A Dynamic Load Control Scheme for Smart Grid Systems," ICSGCE, Chengdu, 2011, pp. 27-30.

[11] Methodology Used in ČEZ Group (Largest Czech Energy Industry Group Owning Generation, Distribution and Trading).

[12] F. Fencl, "Distribution Devices. Script CTU (Czech Technical University)," Prague, 2000.

[13] R. Walawalkar, S. Blumsack, J. Apt and S. Fernands, “An Economic Welfare Analysis of Demand Response in the PJM Electricity Market," Energy Policy, Vol. 36, 2008, pp. 3692-3702. doi:10.1016/j.enpol.2008.06.036

[14] F. Leuthold, H. Weigt and C. Hirschhausen, "Efficient Pricing for European Electricity Networks-The Theory of Nodal Pricing Applied to Feeding-In Wind in Germany," Utilities Policy, Vol. 16, No. 4, 2008, pp. 284-291. doi:10.1016/j.jup.2007.12.003

[15] M. Adamec and O. Starý, "Smart Technologies Implementation into the Energy Industry," The Future of Energy: Global Challenges, Diverse Solutions, Cleveland, IAEE, 2010.

[16] P. Rafaj and S. Kypreos, "Internalisation of External Cost in the Power Generation Sector: Analysis with Global Multi-Regional MARKAL Model,” Energy Ploicy, 2006.

[17] M. Junginger, W. V. Sark and A. Faaij, "Technological Learning in the Energy Sector," Edward Elgar, 2008.

[18] R. Webster, "Can the Electricity Distribution Network Cope with an Influx of Electric Vehicles?" EA Technol- 
ogy, Capenhurst, Chester, CH1 6ES, 1999. doi:10.1016/S0378-7753(98)00262-6

[19] REMODECE Project Data. http://remodece.isr.uc.pt/

[20] A. Pina, C. Silva and P. Ferrão, "The Impact of Demand Side Management Strategies in the Penetration of Renewable Electricity," Energy, Vol. 41, 2012, pp. 128-137. doi:10.1016/j.energy.2011.06.013
[21] R. Weron, "Modeling and Forecasting Electricity Loads and Prices," The Wiley Finance, 2006.

[22] E. Blokhuis, B. Brouwers, E. Putten and W. Schaefer, "Peak Loads and Network Investments in Sustainable Energy Transitions," Energy Policy, Vol. 39, No. 10, 2011, pp. 6220-6233. doi:10.1016/j.enpol.2011.07.021 